\title{
EVIDENCE-BASED PRACTICE: INCLUSIVE EDUCATION FOR THE EFFECTIVE IMPLEMENTATION FOR CHILDREN WITH AUTISM
}

\author{
Emine Ozel Erenand Nik Asilah Nik Ali
}

Department of Educational Psychology and Counselling, Faculty of Education, Kuala Lumpur,Malaysia

\begin{abstract}
Interventions for autism are increasing being held to standards such as 'evidence-based practice' in psychology and 'scientifically-based re-search' in education. At the factor when these ideas rose with regards to psychotherapy and regular education, they brought on substantial debate. Evidence-based practices (EBPs) are the premise on which educators and other specialist coops are required to outline educational programs for students with autism spectrum disorders (ASD). Inclusive education as a late modernity reform project is exemplified in the call for 'Education for All'. Despite the simplicity of its message, inclusion is highly debatable. General education teachers have differing views about the inclusion of students with ASD in mainstream class-rooms. However, the type and severity of the Autistic children's affect teachers' willingness to accommodate certain students and their confidence that they will effectively manage their classrooms. The Implementation science guides the movement of innovations, such as transforming evidence-based practices for students with ASD into regular practices at school. This article is presented as an inclusive educational model to build systems of professional development that increase the quality of services and promote teachers' use of evidence-based practices. Further, it is proposed that the ASD community align with the greater inclusive education reform movement.
\end{abstract}

Keywords: Inclusive education, Autism Spectrum Disorder, Effective Implementation, Evidencebased practice (EBP)

\section{Introduction}

In last decades that an increase in the number of children diagnosed with autism spectrum disorder (ASD) 1 to 1 in 68, family interest for protection scope of evidence-based treatments for ASD has increased.(Roanaet.,al., 2016). The time period evidence-based practice (EBP) has emerge as a commonplace capture phrase over the last ten years, and connection with it may be observed across a number of disciplines. but, at the same time as the notion of evidence-based totally practice is becoming an increasing number of usual as an important attention of teacher work, there is confusion and contradiction concerning its which means. one of the reasons for this is the variety of complicated terminology related to EBP, which include phrases which includes 'best exercise', 'nice evidence', and 'research-based', all of which have been used synonymously with EBP, in spite of differences in their that means (Hornby, Gable \& Evans, 2013).

Evidence-based practices (EBPs) are the basis on which teachers and other service providers are required to design educational programs for learners with autism spectrum dis-orders (ASD).Thus, an increasing number of students with disabilities, including those with ASD, are being educated in inclusive settings around the world (Koegel et al. 2012). In the course of recent decades, there has been a common and widespread drive by international governments towards inclusion as a model for education. In that capacity, inclusion has now become one of the most crucial educational issues internationally. In the twenty-first century inclusive education is considered as the right of every child to be a part of mainstream society. Inclusive education mainly has focused on the position of students with special needs. In many countries these students do not even attend school, let alone a special one. Implementation science provides guidance for moving in-novation, such as utilizing evidence- based practices for students with ASD, into regular practice in schools. The principles of implementation science, the scientific knowledge about evidence-based practices, and the measurement of program quality into an intervention approach for students with ASD. The purpose of this article is to provide educators with a defineion and overview of evidence-based practice, outline rules for recognizing compelling

Corresponding Author:EmineOzelEren/emineozeleren@siswa.um.edu.m 


\section{EmineOzelEren and Nik Asilah Nik Ali/Evidence-Based Practice: Inclusive Education for the Effective Implementation for Children with Autism}

teaching practices and highlight particular resources that educators can utilize students with autism.

\section{Inclusion: Indefinable Constructs}

The basic premise underpinning inclusion is that all children, regardless of ability or disability have a basic right to be educated alongside their peers in their local school. Inclusion is thus generally defined as "providing effective learning opportunities for all pupils". Article 24 of the UN Convention on the Rights of Persons with Disabilities recognizes that education should be accessible "... without discrimination and on the basis of equal opportunity... within an inclusive education system at all levels...". A persist theme in it is generally recognized, regardless, that kids with handicap keep on experiencing distinctive types of avoidance which differ contingent on their inability, residence, and the way of life or class to which they have a place(UNICEF, 2013). In accordance with worldwide guidelines the expression "students with disabilities" refers to those with sensory, communication, motor, learning disabilities and behavior disorders(WHO,2011). Partly resulting from this rights-based approach, there is an intense global debate on implementing inclusive education (Cooper and Jacob 2011; Yeung 2012). This has generated an interest among policy-makers, researchers and practitioners on the question of "how"to make education inclusive.

Inclusive education was defined as characterized by:

- a logic of acknowledgment and having a place inside a group;

- a philosophy of pupil, own family, educator and community collaboration;

- a celebration of the variety and value of all pupils;

- valuing educating pupils in high-quality schools;

- valuing educating pupils alongside their age peers;

- valuing educating pupils in mainstream classrooms;

- valuing educating pupils in schools in their local community (Salend,2011).

-

So it is clear from the above that inclusive education and special education are based on different philosophies and provide alternative approaches to the education of children with special education needs (SEN). In fact, they are now increasingly regarded as diametrically opposed in their approaches to providing education for children with SEN. This is a confusing situation for professionals in the field of education as well as for parents of children with SEN. Inclusion in education is recognized as a basic human right and the foundation for a more just and equal society (European Agency for Development in Special Needs Education, 2012). Interpretation of inclusive education is, however, an increasingly contentious term that challenges educators and educational systems think about the work of teaching and learning in different ways and from varied perspectives (GrimaFarrell, Bain and McDonagh,2011,p.118). Therefore, inclusive education to represent an entire school concern and attempts to adjust specialized curriculum to general education in a way that most adequately and proficiently bestows quality training to all pupils". The issue of value has been a note-worthy drive globally, supporting the development towards a more inclusive education framework and the path in which consideration is characterized (Forlin, 2012).It is also possible that the lack of a tight conceptual focus that inclusive education suffer from may have contributed to the misconception and confused practices (Berlach\& Chambers, 2011).Scholars, practitioners, governments, and organizations such as UNESCO and UNICEF have also provided conceptualizations and definitions of inclusive education.

On the other hand they provide a philosophical framework for inclusive education along with school-based and classroom-based examples(Berlach\& Chambers, 2011). Their philosophical underpinnings consist of the availability of opportunity; acceptance of disability and/or disadvantage; superior ability and diversity; and an absence of bias, prejudice, and inequality. Some inclusive education scholars, conceptualize the task of inclusion as being that which identifies and removes barriers to participation in education (Ainscow, Dyson, Goldrick, \& West, 2011).The special school-regular school dichotomy is no longer a useful way of framing education, and barriers that exist in both sectors need to be removed to create what is, at last, dis-similar to irregular school (Slee,2011), Graham and Slee ,2008). That reference to "Reforming education is a manifold and complex task that reaches into the deep structures of education and schooling to generate distinctive strategies, practices and societies(Slee,2011). An extended perspective of inclusive education permits it to be viewed as a 
human rights issue, with marginalized and excluded groups being discriminated against and denied what is readily available to others in the mainstream.

Following the above definition of inclusion from UNESCO (2012) utilized as a part of this report, schools must be pre-pared to both acknowledge students with different needs and in addition to carry on in proactive approaches to eliminate boundaries to empower full attendance. Schools must receive the elements of inclusion, while in the meantime be set up to dismantle systems and works on prompting to exclusion (Forlin,2013). Measuring, in this way, includes inspecting consideration from the point of view of an entire school approach, for example, proffered by the UNICEF (2010),meaning of "Inclusion is really about how well child-friendly schools are doing at making practical changes so that all children, regardless of their background or ability, can succeed. Inclusive education became list 10 topics:

1. Provision of information

2. Physical features

3. Inclusive school policies

4. The IEP

5. Student interactions

6. Staffing and personnel

7. External links

8. Assessment of achievement

9. Curriculum

10. Teaching strategies (Winter, E., \&O’Raw, P.,2010).

A variety of measures of these features of inclusion has been developed. To accomplish this, most frameworks receive an entire school way to deal with measuring parts of getting to, support, approach, educational modules, instructional method, quality teaching, and appraisal of accomplishment. In light of being signatories to worldwide traditions, governments are required to give affirmations that inability and differing qualities are being tended to, particularly inside an inclusive education field. (Donnelly \& Watkins, 2011).

The objective of inclusion is that children with disabilities have the capacity to take an interest fully in general education. Teachers must bolster the youngster's full cooperation in environment and his or her social integration with ordinarily developing peers. General education teachers ought not simply be required to "follow the educational programs" but rather to "learn the educational modules". These are the students whose needs are special that some modifications within the teaching - learning process are a precondition in order to enable them to fully participate and benefit from the process of inclusive education.

This study will emphasize on the evidence-based teaching strategies that have been found to be very effective and significant particularly for inclusive classrooms. Evidence-based teaching practices, the movement began in pedagogy in the mid-nineties. Evidence-based teaching methodologies are obviously determined teaching techniques that have been shown in research to be effective in bringing about desired outcomes in a delineated population of learners (Das, 2013). This is the integration of professional expertise, learners' ability and the best research evidence into the decision-making the process for teaching-learning in the classroom. For teachinglearning process in inclusive classrooms, evidence-based teaching strategies can play a vital role for quality learning especially for the students with disabilities.

\section{Characteristics of Students with ASD}

Autism is a neurodevelopmental condition that affects social communication in particular. People with autism also have difficulties with restricted or repetitive behaviors and for many, this includes sensory problems (American Psychiatric Association 2013).The forthcoming revised edition of the Diagnostic and Statistical Manual of Mental Disorders (DSM-5) acknowledges this extraordinary inconstancy in the introduction of ASD, and the related trouble of portraying individual disorders inside the mental imbalance range. DSM-5 consolidates the beforehand separated autistic disorder, Asperger's disorder, youth disintegrative con-fusion, and inescapable formative issue not generally indicated, into a solitary disorder (autism spectrum disorder) (American Psychiatric Association 2013).Autism makes it difficult to make sense of the world, disables conventional insight and results in difficulty under-standing and communicating about internal and external 


\section{EmineOzelEren and Nik Asilah Nik Ali/Evidence-Based Practice: Inclusive Education for the Effective Implementation for Children with Autism}

states and behaviors (self and others). The way these characteristics manifest and impact on the person with autism and those around them in both the short and long term depends on the social and environmental context (Prizant 2015). One of the issues in the inclusion process of students with ASD is the severity of the disability from student to student. The factors that can make or break the inclusion process are related to the student's functioning in terms of his her personal $\backslash$ internal factors such as; social skills, communication and language skills, stereotypical behavior and other individual abilities (Eldar, Talmor\& Wolf-Zukerman (2010). Advocates of inclusion suggest that placement of children with ASD in general education settings can lead to academic and social benefits due to reduced isolation and stigma, improved instructor expectations, get admission to an extra stimulating surroundings, and behavioral models from normal students (Rotheram-Fuller et al. 2010). As diagnosis rates and public awareness of autism have improved, so too has the variety of therapeutic processes, strategies and tools on provide, a lot of which might be advertised and advocated through on-line social networking. These interventions might also include extensive claims of fulfillment connected, in spite of not having been carefully evaluated (Stansberry-Brusnahan\& Collet-Klingenberg, 2010) human beings with ASD and their families can be stressed and overwhelmed by means of the plethora of 'medications' accessible to them, and possibly open themselves to intercessions that are incapable or even destructive (Marder\& Fraser, 2012). A number of authors have undertaken research and literature reviews to identify interventions for people with ASD that meet the criteria for EBP (National Autism Center, 2009). At a wide level, there is agreement that the accompanying elements, as components of administration conveyance models, are supported by thorough research evidence:

- Individualized supports and programs

- Relatively established and supportive environments

- Supported transitions among settings

- Practical method to behavior management

- Family involvement.

In spite of the fact that research findings are a crucial issue of EBP, other essential elements must be taken into consideration when designing and delivering programs and interventions for people with ASD. These include professional judgement; data-based decision making; values and preferences of the client and their family; and the capacity of the agent to implement an intervention appropriately (National Autism Center, 2009).Teachers are required to use educational practices based on evidence obtained via quality research.

\section{A New Prospect: Evidence-Based Practice for ASD Students in the Inclusive Education}

The evidence-based teaching techniques which have been observed to be very effective and substantial specifically for inclusive classroom. Evidence-based teaching strategies are clearly specified teaching strategies that have been shown in controlled research to be effective in bringing about desired outcomes in a delineated population of students. For teaching learning method inclusive classrooms, evidence-based teaching techniques can play a crucial function for excellent mastering especially for the students with disabilities (Browder, D. M., Wood, L., Thompson, J., \&Ribuffo, C.,2014).Professionals serving students with autism spectrum disorders (ASD) in inclusive classroom settings face the challenge of selecting and successfully implementing evidencebased intervention strategies. The reason for identifying evidence-based practices is to help consumers and providers choose among intervention approaches. The principally, was explained, what is a practice. For instance, after a meticulous literature search and coding procedure, the National Standards Project (NAC, 2009), on intercessions for people with ASD classified 11 practices as evidence-based:

1. Antecedent package

2. Behavioral package

3. Comprehensive behavioral treatment for young children

4. Joint attention intervention

5. Modeling

6. Naturalistic teaching strategies

7. Peer training package

8. Pivotal response treatment 


\section{Schedules}

10. Self-management

11. Story-based intervention package (NAC, p.43, 2009; Smith, T., 2013).

Two items in this list, modeling and schedules, are specific cuing procedures that have a wide range of applications for individuals with and without ASD. Most different objects are combinations of strategies that change from study to study but, three objects confer with greater standardized packages. Comprehensive behavioral treatment originated inside the work of on early intensive behavioral intervention (EIBI) for infants and preschoolers with ASD. It has advanced into many distinctive models, all of which integrate a multiplicity of intervention approaches that are added 20 to 40 hour per week for 2 to 3 years (Smith, 2011). Crucial reaction treatment is one way to deal with utilizing naturalistic showing techniques, with need given to practices recognized by the designers as particularly imperative for advancing youngsters' improvement (Koegel and Koegel, 2006). Story-based intercession is gotten from a trade-marked program, Carol Gray's Social Stories (Gray, 2004).As recognized in a sharp analysis, the main normal component of every one of the 11 of these things is that each is involved mediation strategies or blends that appear to share center characteristic features (NAC, 2009).An evidence-based practice can be defined as an instructional strategy, intervention, or teaching program that has resulted in consistent positive results when experimentally tested (Mesibov\&Shea, 2011; Simpson, 2005).The usage of astounding exploration is required all together for mediation methodologies to be considered an evidence-based practice(Odom, Collet-Klingenberg, Rogers, \& Hatton, 2010). In addition to, further define "quality" as research that incorporates experimental, quasi-experimental, or single-subject research designs; is replicated multiple times, and is published in peer reviewed professional journals (Boutot and Myles,2011).

Therefore, research excludes evidence this is supported by means of anecdotal reviews, case research, and booklet in non- refereed journals, magazines, the net, and different media information retailers (Boutot and Myles, 2011).The idea of proof based practice started in the medicinal field in the 1970s (Odom et al., 2005) and was embraced into the field of training with the No Child Left Behind (NCLB) Act (NCLB, 2002), in which the expression " scientifically based research" is said more than a hundred times (Simpson, 2005).Special teachers are required by expert norms 'Council for Exceptional Children, 2009' and United States government direction to actualize successful instructive methodologies bolstered by confirmation and research NCLB 2002. As indicated by Mayton, Wheeler, Menendez, and Zhang (2010), the field of a custom curriculum has been defied with a critical crevice amongst research and practice. Systems that are bolstered by research are regularly not put into practice in the classroom.

Furthermore, to assist in enhancing the quality of special education services for children and teenagers with ASD, much work has gone into identifying EBPs (National Autism Center, 2009; Odom, Collet- Klingenberg, Rogers, \& Hatton, 2010). The resources for determining best practices in autism are more complete and accessible than in previous years, however, educators face the challenge of being able to accurately identify those evidence-based practices and then replicate the strategies in the classroom and other educational settings (Stansberry-Brusnahan\& Collet-Klingenberg, 2010). EBP is obligation not only for the field of a specialized curriculum, as well as particularly those teachers liable for teaching children with autism to have firsthand knowledge of evidence-based practices to assist limit the gap among research and exercise. As indicated by the "National Research Council 2001", the training of educators and school faculty is the essential method for guaranteeing that evidence- based coaching procedures are connected when working with pupils with autism. Educators have the benefit of directly being capable of becoming aware of every pupil's special needs and objectives; when they have the information of evidence- based practice in the classroom they are better prepared to coordinate the techniques to the individual needs of every pupil served (Simpson, 2005).For educators attempting to meet the diverse range of learning needs for children with ASD, decisions regarding the types of interventions to implement in the classroom and the limited research on numerous strategies can be both misleading and confusing. Because of that experts' and parental figures' dependence on untested techniques and reliance on procedures that have constrained confirmation have brought about doubtful and absurd desires for understudies and have frustrated the potential advance of understudies with ASD (Simpson, 2005).It is vital for educators, directors, and other school personnel to be informed about evidence- based methods to deal with satisfactorily address the necessities of pupils with autism. 


\section{EmineOzelEren and Nik Asilah Nik Ali/Evidence-Based Practice: Inclusive Education for the Effective Implementation for Children with Autism}

\section{Perspectives on Evidence-Based Concepts and Autism}

There are several clear benefits of an evidence-based approach to autism treatment. The many years in the past empiricism placed an give up to psychodynamic speculations approximately parental the many years in the past empiricism placed an give up psycho-dynamic speculations approximately parental pathology because the cause of autism (Mesibov, G. B., \&Shea, V. (2011).Also, empiricism maintains to allow the field to transport past testimonials and anecdotes from family participants, which in autism have resulted in a few specifically facilitated communication; the management of secretin; chemical chelation of the blood. Add on, empiricism in academic settings can probably counterbalance factors which includes historical traditions, philosophical developments, and political pressures that influence how services for students with autism are prepared and introduced. The Evidence-Based, Individualized Program for Students with Autism (EBIPSA), developed by the NPDC, is an example of such a model. EBIPSA depends on the careful specifications of goals (i.e., behavioral targets or skills), an underlying foundation of program quality, identification of specifically focused intervention practices, implementation with a high degree of fidelity, and training for service providers to ensure ongoing fidelity of implementation. A conceptual framework for this model appears in Figure 1.

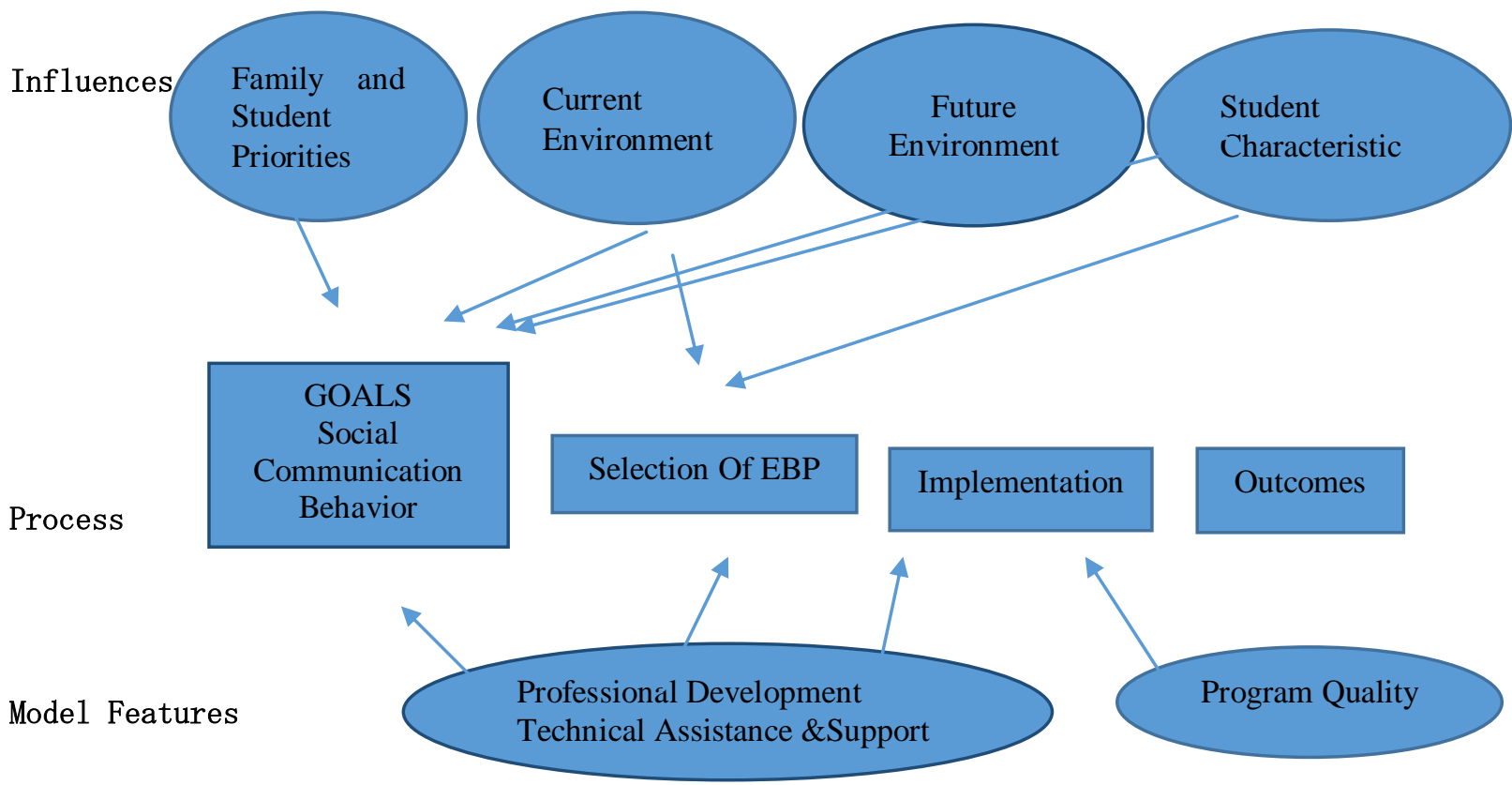

Figure 1. The conceptual framework of the Evidence-Based, Individualized Program for Students with Autism (EBIPSA)(Odom et al.2012)

\section{Evidence-Based, Individualized Program for Students with Autism}

Goals. As with any program of systematic instruction or intervention, carefully specifying the learner's goals, which are also the desired outcomes, is essential. In educational systems, Individualized Family Service Plans (IFSP), Individualized Education Plans (IEP), and Individualized Transition Plans (ITPs) specify goals and benchmarks. Considerations of the requirements of the current and future environments also are critical for designing programs that will operate in inclusive settings for school-age children and youth with ASD. Characteristics of well-developed goals are that they are measurable, functional, and generalizable (Kurth\&Mastergeorge, 2010).

Selection of focused intervention practices. In an individualized intervention approach, the selection of a specifically focused intervention is based on the goals identified, the characteristics of the individuals, and characteristics of the current environment. The teacher/therapist/service provider's capacity to deliver the intervention for instance, the professional development, training, the support they have received in the student's current setting is also a critical part of the decision-making process. For example, some interventions may 
require some classroom modifications such as setting up an independent workstation, arrangements of visual supports and other interventions may only be feasible when typical peers are available for peer-mediated interventions.

Implementation. As noted previously, the measurement of implementation and fidelity in programs for children and youth with ASD has been a weakness in the autism intervention literature.

Program quality. Similar in concept to the common factors of psychotherapy sessions, program quality is features of a program, such as a team collaboration, program ecology, and family participation, which apply to all learners with ASD in the program. Examples of quality include program structure, social climate, communicative environment, opportunities for independence, assessment, family participation, and teaming. Researchers with NPDC have developed a measure of pro-gram quality called the Autism Program Environments Rating Scale “APERS; APERS Development Group, 2011”, which is based on direct observation in the program, interviews with the staff and families, and review of records. In the EBIPSA framework, the APERS is used to document and improve pro-gram quality before designing specific intervention programs for students with ASD (APERS Development Group, 2011).

Professional development, training, and support. With goal development, choice from among 27 EBPs to apply to multiple goals for multiple students, and a focus on assessment and improvement of program quality, the EBIPSA model would be daunting for any practitioner without sufficient preparation, training, and coaching. (Odom, S. L., Hume, K., Boyd, B., \&Stabel , A., 2012).

Evaluation. The EBIPSA model is a technically eclectic approach with a central conceptual framework having clearly articulated features (i.e., systematic assessment and goal generation, evidence-based, focused intervention practices, program quality, and professional development). It is based solidly on applied behavioural analysis intervention practices as well as practices emerging from other applied research, and the procedures have been "manualized" (Smith, T. (2013). Twenty-seven practices met the standards for being evidence-based. These practices with their definitions seem in table 1.

Table 1

\begin{tabular}{|l|l|}
\hline Evidence-based practice & \multicolumn{1}{|c|}{ Descriptor } \\
\hline Behavioral strategies & $\begin{array}{l}\text { Arrangement of events or circumstances that precede the occurrence of an } \\
\text { interfering behavior and designed to lead to the reduction of the behavior }\end{array}$ \\
\hline $\begin{array}{l}\text { Antecedent-based } \\
\text { intervention (CBI) }\end{array}$ & $\begin{array}{l}\text { Instruction on management or control of cognitive processes that lead to } \\
\text { changes in overt behavior }\end{array}$ \\
\hline Prompting & Behaviorally based antecedent teaching strategy \\
\hline Reinforcement & Behaviorally based consequence teaching strategy \\
\hline Task analysis and chaining & $\begin{array}{l}\text { Behaviorally based antecedent teaching strategy that breaks down steps } \\
\text { and links them for prompting }\end{array}$ \\
\hline Time delay & $\begin{array}{l}\text { Behaviorally based antecedent teaching strategy that promotes errorless } \\
\text { learning }\end{array}$ \\
\hline Computer-aided instruction & The use of computers for varied instruction \\
\hline $\begin{array}{l}\text { Discrete trial training (DTT } \\
\text { Naturalistic interventions }\end{array}$ & $\begin{array}{l}\text { One-to-one instructional strategy that teaches skills in a planned, } \\
\text { controlled, and systematic manner }\end{array}$ \\
\hline $\begin{array}{l}\text { A variety of strategies that closely resemble typical interactions and occur } \\
\text { in natural settings, routines and activities }\end{array}$ \\
\hline $\begin{array}{l}\text { Parent-implemented } \\
\text { interventions }\end{array}$ & $\begin{array}{l}\text { Strategies that recognize and use parents as the most effective teachers of } \\
\text { their children }\end{array}$ \\
\hline Peer-mediated instruction/ & $\begin{array}{l}\text { Strategies designed to increase social engagement by intervention (PMII) } \\
\text { teaching peers to initiate and maintain interactions }\end{array}$ \\
\hline
\end{tabular}


EmineOzelEren and Nik Asilah Nik Ali/Evidence-Based Practice: Inclusive Education for the Effective Implementation for Children with Autism

\begin{tabular}{|c|c|}
\hline $\begin{array}{l}\text { Picture exchange } \\
\text { communication }\end{array}$ & $\begin{array}{l}\text { A system for communicating that uses the physical system (PECS) } \\
\text { handing over of pictures or symbols to initiate communicative functions }\end{array}$ \\
\hline $\begin{array}{l}\text { Pivotal response training } \\
(P R T)\end{array}$ & $\begin{array}{l}\text { An approach that teaches the learner to seek out and respond to naturally } \\
\text { occurring learning opportunities }\end{array}$ \\
\hline \multicolumn{2}{|c|}{ Positive behavioral support strategies: } \\
\hline Functional behavior & $\begin{array}{l}\text { A systematic approach for determining the underlying assessment (FBA) } \\
\text { function or purpose of behavior }\end{array}$ \\
\hline Stimulus control/ & $\begin{array}{l}\text { The modification or manipulation of environmental modification aspects } \\
\text { known to impact a learner's behavior }\end{array}$ \\
\hline Exercise $($ ECE) & $\begin{array}{l}\text { Increase in physical exertion as a means of reducing problem behaviors or } \\
\text { increasing appropriate behavior }\end{array}$ \\
\hline $\begin{array}{l}\text { Response } \\
\text { interruption/redirection }\end{array}$ & $\begin{array}{l}\text { The physical prevention or blocking of interfering behavior with } \\
\text { redirection to more appropriate behave }\end{array}$ \\
\hline $\begin{array}{l}\text { Functional communication } \\
\text { training }(F C T)\end{array}$ & $\begin{array}{l}\text { A systematic practice of replacing inappropriate or training (FCT) } \\
\text { ineffective behavior with more appropriate or effective behaviors that serve } \\
\text { the same function }\end{array}$ \\
\hline Extinction & $\begin{array}{l}\text { Behaviorally based strategy that withdraws or terminates the rein-forcer of } \\
\text { an interfering behavior to reduce or eliminate the behavior }\end{array}$ \\
\hline Differential reinforcement & $\begin{array}{l}\text { Behaviorally based strategies that focus reinforcement (DRA /I/O/L) on } \\
\text { alternative, incompatible, other, or lower rates of the interfering behavior } \\
\text { in order to replace it with more appropriate behavior }\end{array}$ \\
\hline Self-management & $\begin{array}{l}\text { A method in which learners are taught to monitor, record data, report on, } \\
\text { and reinforce their own behavior }\end{array}$ \\
\hline Social narratives & $\begin{array}{l}\text { Written narratives that describe specific social situations in some detail } \\
\text { and are aimed at helping the individual to adjust to the situation or adapt } \\
\text { their behavior }\end{array}$ \\
\hline Social skills training groups & $\begin{array}{l}\text { Small group instruction with a shared goal or outcome of learned social } \\
\text { skills in which participants can learn, practice, and receive feedback }\end{array}$ \\
\hline Structured work systems & $\begin{array}{l}\text { Visually and physically structured sequences that provide opportunities for } \\
\text { learners to practice previously taught skills, concepts, or activities }\end{array}$ \\
\hline Video modeling & $\begin{array}{l}\text { Utilizes assistive technology as the core component of instruction and } \\
\text { allows for pre-rehearsal of the target behavior or skill via observation }\end{array}$ \\
\hline Visual supports & Tools that enable a learner to independently track events and activities \\
\hline $\begin{array}{l}\text { VOCA /Speech Generating } \\
\text { Devices }\end{array}$ & $\begin{array}{l}\text { Electronic, portable devices used to teach learners (SGD) communication } \\
\text { skills and as a means of communication. }\end{array}$ \\
\hline
\end{tabular}

Note: Reprinted with permission from "Evidence-Based Practices in Interventions for Children and Youth with Autism Spectrum Disorders," by S. L. Odom, L. Collet-Klingenberg, S. J. Rogers, and D. D. Hatton, 2010, Preventing School Failure, 54, 275-282.

The evidence based practices include interventions which might be essential implemented behaviour evaluation techniques such as reinforcement, extinction, prompting, assessment and analytic techniques which might be the basis for intervention, such as, function-al behaviour assessment, task analysis, and combinations of commonly behavioural practices utilized in ordinary and systematic manner that fit collectively as replicable method for in-stance, functional communication training, pivotal response training. Additionally, the method through which an intervention is introduced defines some practices for examples, discern carried out interventions, technologyaided interventions

The wide variety of researches identified in assist of each practice also appears in table 1.As stated, single Case design (SCD) be-came the predominant design method employed, and some practices had very strong assist in terms of the number of research that documented their efficacy for instance, antecedent-based intervention, 
differential reinforcement, prompting, reinforcement, video-modelling that different practices had strong assist from research the use of either SCD or group design methodology such as, parent implemented interventions, social narratives, social skills training, technology-aided training, and intervention, visual helps. However any practices have been completely supported through group design methodologies.

\section{Teacher and Peers Experiences In Inclusive Settings}

It is essential to understand the current practices used to foster inclusive education for students with autism spectrum disorders (ASDs) as well as factors related to the implementation of classroom interventions. An important factor in deter-mining the success of inclusion is the attitude of the teacher. Teachers' attitudes toward inclusion vary across the educational field, and numerous studies have involved teachers' attitudes toward inclusion. As appeared in the accompanying audit, some of these reviews utilized the term joining or mainstreaming, though others utilized inclusion. Regardless of the distinctive phrasing, all appeared to allude to a circumstance in which a class, a school, or an instructive framework tries to address the issues of students with special needs.

The attitude of students with autism towards socializing with peers was mixed; some preferred to spend time by them-selves, others enjoyed socializing as long as it was in the con-text of a conversation of interest to them, while others found coping with 'normal' social and academic daily situations stressful (Saggers, Hwang, and Mercer 2011; Sciutto et al. 2012).Typical peers were willing to assist students with autism and support communication with them in class but this was less evident during recess. Teachers felt that they were required to facilitate interaction between students with autism and their peers (Soto-Chodiman, Pooley, and Taylor 2012). The tendency for students with autism to behave differently from their peers and their difficulties or lack of skills in responding to social situations resulted in students with autism experiencing isolation, teasing and bullying, which were perceived by students, parents and education professionals to be frequently encountered by students with autism (Gray and Donnelly 2013; Hedges et al. 2014; Humphrey and Lewis 2008; Humphrey and Symes 2011; Johansson 2014; Saggers, Hwang, and Mercer 2011; Sciutto et al. 2012)

UNESCO (1994), various international declarations enacted on inclusive education have given the rights to all children to access education in mainstream settings. Research had demonstrated that youngsters with disabilities displayed better social skills and educational success when they found out in the same environment with their normally developing students (Koegel et al.2011).Inclusive education is very crucial because it affords to get admission to high-quality education for children with disabilities. Isolation in education reasons worry, discrimination, and prejudice in the direction of human beings with the disability. All children need an education so as to assist them in constructing friendship and prepare them for future lifestyles. On top of this, inclusive schooling assists youngsters with disabilities in decreasing the anxiety in building friendship and achieving respect from without disability students. The importance of reforming teacher education to successfully implement inclusive education has been recognized for many years (Armstrong, \&Spandagou, 2010; Forlin, Loreman, \& Sharma, 2014; Savolainen, Engelbrecht, Nel, \&Malinen, 2012).According to Forlin, (2013),teacher education globally, however, has not yet responded to this call. In a comprehensive review of research on teacher and inclusive education commissioned by UNESCO, Rieser (2013),reported that:

The providers of education for pre-service teachers around the world are still largely operating from a teachercentered pedagogy and have little recent and relevant experience. They do not teach inclusive education principles. When children with disabilities are covered it is in discrete courses based upon the old deficit medical model approach. Student teachers and their educators have little practical experience in inclusive settings. Teacher educators have low status and little scrutiny of what they are doing and how effective it is. There is a reticence amongst the more progressive academics to use categorical approaches to impairment for fear of regressing into segregate medical model approaches (Reiser, 2013, p. 136).Furthermore inclusive schooling quality teacher training will become important to make certain that principals and teachers are cognizant of the knowledge of inclusive education and the way to guide newcomers with ASD students in their classes. In general education settings, focusing at the attitudes of teachers in the direction of youngsters with autism is crucial because it can provide an invaluable source of in-formation used .Within the improvement of teacher education and professional development applications(Park \&Chitiyo, 2011).The significance of teachers within the successful implementation of inclusion is obvious considering that teachers are the people charged with enforcing and facilitating inclusive practice with all youngsters in a mainstream setting (Boyle et al., 2012). 


\section{EmineOzelEren and Nik Asilah Nik Ali/Evidence-Based Practice: Inclusive Education for the Effective Implementation for Children with Autism}

\section{FAMILIES WITH CHILDREN WITH ASD and THEIR EXPERIENCES in the INCLUSIVE EDUCATION}

This system know-how that parents need to additionally keep in mind that they also play a crucial function in supporting their toddler in addition to the classroom teacher for the a success implementation of inclusive practices. Inclusion for policy makers could suggest that families and youngsters who have been excluded for decades (e.g., youngsters with disabilities) technique a school to sign up their child. Most significantly, it also approach that the school gets the essential assist to teach the child (Sharma, U.2011).

Close collaboration between families and schools is an effective way to create a successful home-school partnership. Family involvement and communication between the home and school are vital in special education. Using a communication log or notebook that the inclusion teacher, the special education teacher, and parents can send back and forth daily or weekly to help maintain communication is indeed crucial. The student will feel more a part of the mainstream education classroom if his or her teacher and parents are on the same page and in regular communication (Boutot, 2007). Also, it is recognized that parents play a key role for the ASD treatment. More specifically, physicians and other healthcare professionals can provide support to parents by educating them about ASD; providing anticipatory guidance; training and involving them as co- therapists; assisting them in obtaining access to re-sources; providing emotional support through traditional strategies such as empathetic listening and talking through problems(Marcus, Kunce\&Schopler, 2005).

Parental involvement not only benefits students and creates active participation by the parents in the school community, but also increases parental satisfaction in the processes related to inclusive education(Timmons and Breitenbach, 2004).Parents' choice of not to have their child formally diagnosed created issues for educators, such as ineligibility for resources, and made managing concerns from other parents more challenging. Educators' perceived lack of disclosure made creating an atmosphere of peer acceptance and promoting peer understanding more difficult and increased the risk of students with autism being excluded (Lindsay et al. 2013) Parents viewed inclusion as providing their child with a better chance of a 'normal' daily life .

\section{Discussion}

A current audit of studies utilizing single-case research plans demonstrated an adequate number of studies with methodological quality giving empirical evidence to bolster the utilization of behaviorally based interventions as the method for enhancing social attitudes of pupils with ASD in general education (Camargo et al. 2014).As a consequence of that significant factors concerning their effectiveness in inclusive classrooms nevertheless is require to be addressed. Despite the fact that present research provide treasured information which could assist teachers and practitioners to choose evidence based practices to facilitate social interaction of youngsters with ASD in general education, additional information remains needed.

The large increase in the number of students with an autism educational classification (Pinborough-Zimmerman et al.,2012),combined with budgetary worries in urban school areas, represents a pickle to teachers, managers, and parents. Members illustrated the numerous and shifted difficulties to giving best practices to ASD treatment in government funded schools, some of which are reliable with past research (Kasari and Smith, 2013; Lindstrom,2013).

It is crucial that, adjusting the configuration of training and the medicines themselves may bring about mediations that are all the more viably dispersed (Iadarolaet. Al.2015).Despite the fact that, for teachers who are as of now loaded with expert advancement exercises, online or video guideline may help them get to ASDparticular preparing all the more effectively. Concerning, modular approaches (Kasari and Smith, 2013), and school-wide programs are called "Positive Behavioral Interventions and Supports" (Horner et al., 2009) are individualized and evidence-based. These mediations adopt a more extensive strategy than a portion of the specific procedures, for example, discrete trial preparing to utilized for pupils with ASD, and they, in this way, might be less demanding to coordinate into existing proficient advancement learning activities.

According to education professionals, inclusion provided students with autism the opportunity to engage in more academic tasks, and the use of class-wide strategies to address behavior and social issues which benefitted all students (Sansosti and Sansosti 2012).Social communication characteristics of autism and relation-ships 
emerge as a key mediator of success school. All aspects of school life from learning in class to relating to peers in the playground were perceived by stakeholders to be negatively impacted by student communication limitations.

Meanwhile, a crucial enabler for the implementation of EBPs is having effective professional improvement for teachers. That enlightened professional improvement consists of several key factors (Odom,2009). First, team building and collaboration need to be constructed into the method. Second, specialists or coaches ought to provide demonstrations of the EBPs in class-room settings and observe up with remarks to teachers on their use of EBPs. Third, teachers ought to form groups of practice with the intention to share information and reflections on the advent of EBPs into their classrooms. Fourth, on-line resources, together with video clips of EBPs being utilized in lecture room settings, can be accessed to provide useful facts and tips on their use. Fifth, internetprimarily based video and interactive structures, consisting of wikis and video remarks, may be used to assist the implementation of EBPs. Besides the want for powerful expert improvement and step-by way of-step tactics for implementing EBPs, it is also essential for the successful use and maintenance of EBPs that instructors have assist in using them (Torres, Farley, \& cook, 2012).

This support desires to come back from each faculty administrators and instructors' colleagues, including mainstream lecture room teachers and experts in inclusive and special training. It is good to set up a network of exercise so teachers can help each other inside the use of EBPs. They are able to then proportion their stories and produce practice-based evidence to monitor and evaluate the effectiveness of EBPs of their unique settings. The parents and educators said positive and negative outcomes in phrases of the attitude of others closer to students recognized with autism suggesting know-how of the diagnosis led to 'autistic expectancies' of youngsters even as the lack of expertise ended in misunderstanding of 'autistic' behaviors and elevated the risk of exclusion. However, educators felt strongly that labeling resulted in get admission to resources. even as most parents believed that inclusion gave their kids a better risk to have a 'normal existence', simplest a mild majority expressed satisfaction with the inclusion of their child suggesting that many believed main-stream placement was not working for their child. There has been an extensive gap inside the studies when it comes to the perspectives of people with autism, and as an end result, lack of expertise about their perspective of the problem.

\section{Conclusion}

This article that there is now an extensive and rapidly growing international literature on evidence-based practice in education. Increasing numbers of students with autism enrolled in mainstream schools mean it is highly likely that teachers will have one or more students with autism in their classes each year. Autism is no longer a rare condition or only the preserve of special education, students with autism are increasingly the business of regular schools, yet what little we know of educational outcomes for these students to date suggests that students with autism are not doing as well as we would expect given their evident cognitive abilities, or compared to other students with and without disabilities. For students with disabilities, education will support their inclusion into regular education through the use of strategies, systems and particular materials. Meanwhile, for those special needs students such as ASD pupils not ready to be incorporated into regular education classrooms, an inclusive education program will be created to react to their individual adapting needs. This inclusive education program incorporates introduction to parents and additionally guardians and to educators in fundamental training that get students $\backslash$ with special educational needs"' school in life.

Fortunately, the emerging field of implementation science may provide the needed guidance for such a translational process (Fixsen, Blase, Metz, \& Van Dyke, 2013), and professional development models for teachers and service providers working with children and youth with ASD have begun to adopt an implementation science approach (Odom, Cox, \& Brock, 2013). All of this points to the fact that from science to practice is a clear challenge and furthermore an imperative next stride for the field (Wong et al.,2014). One approach to improving services to students with ASD enrolled public school programs is through professional development. Consequently, that successful implementation of EBP, is dependent on a multilayered, problem solving process, that must explore the delicate balance between research, the practitioner as a teacher and the pupils and parents. 


\section{References}

Ainscow, M., Dyson, A., Goldrick, S., \& West, M. (2011). Developing equitable education systems. Abbingdon, UK: Routledge.

American Psychiatric Association. 2013. Diagnostic and Statistical Manual (DSM-5). 5th ed. Arlington, VA: American Psychiatric Publishing.

APERS Development Group. (2011). Autism Program Environment Rating Scale (preschool/ elementary and middle/high school). Chapel Hill: National Professional Development Center on ASD, FPG Child Development Institute, University of North Carolina at Chapel Hill.

Armstrong, A.C., Armstrong, D.A., and Spandagou, I. (2010) Inclusive Education: International Policy and Practice, London: Sage Publications. Journal of Research in Special Educational Needs, 10(3). DOI: 10.1111/j.1471-3802.2010.01177_2.x

Berlach, R. G., \& Chambers, D. (2011). Inclusivity imperatives and the Australian National Curriculum. The Educational Forum, 75 (1), 52-65.

Boutot, E. (2007). Fitting in: Tips for promoting acceptance and friendships for students with autism spec-trum disorders in inclusive classrooms. Intervention in School and Clinic, 42, no. 3: 156-61. doi: 10.1177/1053451

Boutot, E. A., \& Myles, B. S., (2011). Autism spectrum disorders: Foundations, characteristics, and effective strategies. Pearson Education, Inc.: Upper Saddle River, NJ.

Boyle, C., Topping, K., Jindal-Snape, D., \& Norwich, B. (2012). The importance of peer support for teaching staff when including children with special educational needs. School Psychology International, 33(2), $167-184$. doi:10.1177/0143034311415783

Browder, D. M., Wood, L., Thompson, J., \&Ribuffo, C. (2014). Evidence-based practices for students with severe disabilities (Document No. IC-3). Retrieved from University of Florida, Collaboration for Effective Educator, Development, Accountability, and Reform Centerwebsite: http://ceedar.education.ufl.edu/tools/innovation-configurations

Camargo, S. P. H., Rispoli, M., Ganz, J., Hong, E., Davis, H., \& Mason, R. (2014). A review of the quality of behaviorally-based intervention research to improve social interaction skills of children with ASD in inclusive settings. Journal of Autism and Developmental Disorders, 44, 2096-2116.

Cooper and Jacob (2011) From Inclusion to Engagement: Helping Students Engage with Schooling through Policy and Practice ISBN: 978-0-470-66484-1258 pages

Das, Asim 2013, Identifying Evidence-Based Teaching Strategies that Teachers Use in Inclusive Primary Classrooms in Southern Bangladesh.Journal of Educational and Social Research MCSER Publishing, Rome-Italy Vol. 3 No. 7 October 2013 Doi:10.5901/jesr.2013.v3n7p639639

Donnelly, V., \& Watkins, A. (2011).Teacher education for inclusion in Europe. Prospects, 41, 341-353. doi: 10.1007/s11125-011-9199-1

Eldar, E., Talmor, R., \& Wolf-Zukerman, T. (2010).Successes and difficulties in the individual inclusion of children with Autism Spectrum Disorder (ASD) in the eyes of their coordinators, International Journal of Inclusive Education, 14(1), 97-114

Fixsen, D., Blase, K., Metz, A., \& Van Dyke, M. (2013). Statewide implementation of evidence-based programs. Exceptional Children, 79, 213-232.

Forlin, C. (2013). Issues of Inclusive Education in the 21st Century. Journal of Learning science No.6, 67-81.

Forlin, C. (Ed.). (2012). Future directions for inclusive teacher education: An international perspective. New York: Routledge.

Forlin, C., Loreman, T., \& Sharma, U. (2014). A system-wide professional learning approach about inclusion for teachers in Hong Kong. Asia-Pacific Journal of teacher Education, 42(3),247-260. 
Graham, L.J., \&Slee, R. (2008). An illusory interiority: Interrogating the discourse/s of inclusion. Educational Philosophy and Theory, 40(2), 247-60.

Gray, C.A. (2004). Social Stories ${ }^{\mathrm{TM}}$ 10.1: The new defining criteria and guidelines. Jenison Autism Journal: Creative Ideas in Practice, 15(4), 2-21.

Grima-Farrell, C. R., Bain, A., \&McDonagh, S. H. (2011). Bridging the research-to-practice gap: A review of the literature focusing on inclusive education. Australasian Journal of Special Education, 35(2), 117-136. DOI:10.1375/ajse.35.2.117.

Hornby, G., Gable, R. A., \& Evans, W. (2013). Implementing evidence-based practice in education: What international literature reviews tell us and what they don't.Preventing School Failure: Alternative Education for Children and Youth, 57(3), 119-123.

Horner, R., Sugai, G., Smolkowski, K., Eber, L., Nakasato, J., Todd, A., \& Esperanza, J., (2009). A randomized, wait-list controlled effectiveness trial assessing schoolwide positive behavior support in elementary schools. Journal of Positive Behavior Interventions, 11, 133-145.

http://dx.doi.org/10.1080/1359866X.2014.906564

Humphrey, N., and S. Lewis. 2008. "“Make Me Normal': The Views and Experiences of Pupils on the Autistic Spectrum in Mainstream Secondary Schools." Autism 12: 23-46.

Humphrey, N., and W. Symes. 2011. "Peer Interaction Patterns among Adolescents with Autistic Spectrum Dis-orders (ASDs) in Mainstream School Settings." Autism 15: 397-419.

Iadarola, S., S. Hetherington, C. Clinton, M. Dean, E. Raeisinger, L. Huynh, J. Locke, et al. 2015. "Services for Children with Autism Spectrum Disorder in Three, Large Urban School Districts: Perspectives of Parents and Educators." Autism19: 694-703.

Johansson, S. 2014. “'He Is Intelligent but Different': Stakeholders' Perspectives on Children on the Autism Spectrum in Urban Indian School Context." International Journal of Disability, Development and Education 61: 416-433.

Kasari C and Smith T (2013) Interventions in schools for children with autism spectrum disorder: methods and recommendations. Autism 17: 254-267.

Koegel, L., Kuriakose, S., Singh, A., \&Koegel, R. (2012).Improving generalization of peer socialization gains in inclusive school settings using initiations training. Behavior Modification, 36(3), 361-377.

Koegel, L., Matos-Fredeen, R., Lang, R., \&Koegel, R. (2011). Interventions for children with autism spectrum disorders in inclusive school settings. Cognitive and Behavioral Practice, 18(3), 421-588.

Koegel, R. L., \&Koegel, L. K. (2006). Pivotal response treatments for autism: Communication, social, and academic development. Baltimore, MD: Paul H Brookes Publishing.

Kurth J, Mastergeorge A (2010) Academic and cognitive profiles of students with autism: implications for classroom practice and placement. International Journal of Special Education 25(2): 8-14.

Lindsay S, Proulx M, Thomson N, Scott H. (2013)Exploring educator's challenges of including children with autism spectrum disorder in mainstream classes. International Journal of Disability, Development and Education; 60:347-362

Lindstrom JH (2013) Introduction to the special issue: response to intervention within the context of specific learning disabilities, emotional disturbance, autism spectrum disorders, and early childhood special education. Exceptionality 21: 1-4.

Marcus, L., Kunce, L., \&Schopler, E. (2005). Working with families. In F. Volkmar, R. Paul, A.Klin, \& D. Cohen (Eds.), Handbook of autism and pervasive developmental disorders (pp.1055-1086). Hoboken, NJ: Wiley.

Marder, T., \& Fraser, D. (2012). Evidence-based practice for special educators teaching students with autism. Special Education Journal, (7). Retrieved from 


\section{EmineOzelEren and Nik Asilah Nik Ali/Evidence-Based Practice: Inclusive Education for the Effective Implementation for Children with Autism}

Mayton, M. R., Wheeler, J. J., Menendez, A. L., and Zhang, J. (2010). An analysis of evidence-based practices in the education and treatment of learners with autism spectrum disorders. Education and Training in Autism and Developmental Disabilities, 45, 539-551.

Mesibov, G. B., \&Shea, V. (2011). Evidence-based practices and autism. [Review]. Autism, 15(1), 114-133.

National Autism Center (2009). Evidence-based practice and autism in the schools: a guide to providing appropriate interventions to students with autism spectrum disorders. Randolph, MA: National Autism Center.

Odom, S. L. (2009). The tie that binds: Evidence-based practice, implementation science, and early intervention. Topics in Early Childhood Special Education, 29, 53-61. http://dx.doi.org/10.U77/0271121408 329171

Odom, S. L., Collet-Klingenberg, L., Rogers, S., \& Hatton, D. (2010). Evidence-based practices for children and youth with autism spectrum disorders. Preventing School Failure, 54, 275-282

Odom, S. L., Cox, A., \& Brock, M. (2013). Implementation science, professional development, and autism spectrum disorders: National Professional Development Center on ASD. Exceptional Children, 79, 233-251

Odom, S. L., Hume, K., Boyd, B., \&Stabel, A. (2012). Moving beyond the intensive behavior treatment vs. eclectic dichotomy: Evidence-based and individualized programs for learners with ASD. Behavior Modification, 36, 270-297. http://dx.doi.org/10.1177 /0145445512444595

Odom, S., Brantlinger, E., Gersten, R., Horner, R., Thompson, B., \& Harris, K. (2005). Research in special education: Scientific methods and evidence-based practices. Exceptional Children,71(2), 137-148.

Park, M. \&Chitiyo, M. (2011).An examination of teacher attitudes towards children with autism, Journal of Research in Special Educational Needs, 11(1), 7078.

Pinborough-Zimmerman J, Bakian AV, Fombonne E, et al. (2012) Changes in the administrative prevalence of autism spectrum disorders: contribution of special education and health from 2002-2008. Journal of Autism and Developmental Disorders 42: 521-530.

Prizant, B. M. 2015. Uniquely Human: A Different Way of Seeing Autism. New York: Simon \& Schuster.

Reiser, R. (2013). Teacher education for children with disabilities: a Literature review.p,136

Roane, H. S., Fisher, W. W., \&Carr, J. E. (2016). Applied Behavior Analysis as Treatment for Autism Spectrum Disorder. Journal Of Pediatrics, 17527-32. doi:10.1016/j.jpeds.2016.04.023

Rotheram-Fuller, E., Kasari, C., Chamberlain, B., \& Locke, J. (2010). Social involvement of children with autism spectrum disorders in elementary school classrooms. Journal of Child Psychology and Psychiatry, 51(11), $1227-1234$.

Saggers B. , Hwang Y.\& K.L. Mercer (2011). Your voice counts: Listening to the voice of high school students with autism spectrum disorder. Australasian Journal of Special Education, 35, $173-190$. doi:10.1375/ajse.35.2.173

Salend, S. J. (2011). Creating inclusive classrooms: Effective and reflective practices (7thed.). Columbus, OH: Pearson Education.p-39.

Sansosti, J. M., \&Sansosti, F. J. (2012). Inclusion for students with high-functioning autism spectrum disorders: Definitions and decision making. Psychology in the Schools, 49, 917-931.

Savolainen, H., Engelbrecht, P., Nel, M., \&Malinen, O. (2012). Understanding teachers' attitudes and selfefficacy in inclusive education: Implications for pre-service and in service teacher. European Journal of Special Needs Education, 27(1), 51-68. http://dx.doi.org/10.1080/08856257.2011.613603

Sciutto, M., S. Richwine, J. Mentrikoski, and K. Niedzwiecki. 2012. "A Qualitative Analysis of the School Experiences of Students with Asperger Syndrome." Focus on Autism and Other Developmental Disabilities 27 (3): $177-188$.

Sharma, U. (2011). Teaching in inclusive classrooms: Changing heart, head, and hand. Bangladesh Education Journal, 10 (2), 7-18. 
Simpson, R. (2005). Evidence-based practices and students with autism spectrum disorders. Focus on Autism and Other Developmental Disabilities, 20(3), 140-149.

Slee, R. (2011). The irregular school: Exclusion, schooling, and inclusive education. Abbingdon, UK: Routledge.

Smith, T. (2013). What is evidence-based behavior analysis ?The Behavior Analyst,36, 7-33.[PubMed],[Web of Science $[$ ]

Soto, R. E., Pooley, J. , Cohen, L. , \& Taylor, M. F. (2012). Students with ASD in mainstream primary education set-tings: Teachers' experiences in Western Australian class-rooms. Australasian Journal of Special Education, 36(2), 97-111.

Stansberry- Brusnahan, L. L., \& Collet- Klingenberg, L. L. (2010). Evidence-based practices for young children with autism spectrum disorders: Guidelines and recommendations from the National Resource Council and National Professional Development Center on Autism Spectrum Disorders. International Journal of Early Childhood Special Education, 2, 45-56.

Timmons, V., \&Breitenbach, M. (2004). A model of teacher support for children with autism: a Prince Edward Island story. Education Canada, 44(1), 52-53.

Torres, C., Farley, C. A., \& Cook, B. G. (2012). A special educator's guide to successfully implementing evidence-based practices. Teaching Exceptional Children, 45, 64-73.

UNESCO (1994) The Salamanca Statement and Frame-work for Action on Special Needs Education. Salamanca, Spain: UN.

UNESCO (2009)United Nations Educational, Scientifics \&Cultural Organization Policy Guidelines on Inclusion in Education. France: Author.

UNESCO (2012). Education: Addressing exclusion. Retrieved from:http://www.unesco.org/new/en/education/themes/strengthening-education-systems/inclusiveeducation/.

UNICEF (2010). Assessing child-friendly schools: A guide for program managers in East Asia and the Pacific, p. 31. Retrieved from: http://www.unicef.org/eapro/Assessing_CFS.pdf.

UNICEF (2013, May). The state of the world's children: Children with a disability. Retrieved from: http://www.unicef.org/publications/files/SWCR2013_ENG_Lo_res_24_Apr_2013.pdf.

WHO (2011).World Health Organization World Report on Disability. Switzerland WHO Press.

Winter, E., \&O'Raw, P. (2010). A literature review of the principles and practices relating to inclusive education for children with special educational needs. Trim, Ireland: National Council for Special Education.

Wong, C., Odom, S. L., Hume, K. Cox, A. W., Fettig, A., Kucharczyk, S., ... Schultz, T. R. (2014). Evidencebased practices for children, youth, and young adults with Autism Spectrum Disorder. Chapel Hill: The University of North Carolina, Frank Porter Graham Child Development Institute, Autism Evidence-Based Practice Review Group.

Yeung, A. S. (2012). Exploring organizational perspectives on implementing educational inclusion in mainstream schools. International Journal of Inclusive Education, 16(7), 675-690. 